\title{
Electronic Ballast Design for UV Lamps Based on UV Dose, Applied to Drinking Water Purifier
}

\author{
Luis De Oro Arenas, Student Member, IEEE, Guilherme de Azevedo e Melo, \\ and Carlos Alberto Canesin, Senior Member, IEEE
}

\begin{abstract}
This paper presents a design methodology for an electronic ballast applied to ultraviolet radiation (UV) lamps for a drinking water purifier, providing adjustable UV dose in order to ensure the inactivation of microorganisms' reproduction, commonly found in untreated water, which can be harmful to human health. The design methodology is based on the multiple segment summation source model, used for defining the UV dose applied to penstock purifiers, considering immersed lamps on a water slide enclosure, which in combination with its hydraulic behavior, provide a good performance for the microorganisms UV absorption along the entire purifier structure ducts. Thus, the water purifier was designed using hydrostatic simulations, in order to ensure compliance with the NSFIANSI Standard 55, for commercial and residential applications. Thereby, an electronic ballast that guarantees a controlled preheating process for the UV lamp electrodes before its ignition and sets the nominal power point on the steady state, was implemented in order to guarantee the designed UV dose. Furthermore, the ballast incorporates a power factor correction flyback input rectifier stage, in discontinuous conduction mode, with universal input voltage range $\left(90 \mathrm{~V}_{\mathrm{rms}}-240 \mathrm{~V}_{\mathrm{rms}}\right)$, attending the limits imposed by IEC 61000-3-2 Standard, for class-C devices.
\end{abstract}

Index Terms-Drinking water, electronic ballast design, multiple segment summation source (MSSS) model, ultraviolet (UV) dose, UV lamp, UV radiation, water purifier.

\section{INTRODUCTION}

W ATER is the basic sustenance for the vital functions development of all living beings. However, due to population growth and its sanitation problems, including its large industrial activities, big part of this essential liquid has ended in contamination state, that is highly harmful to humans, making of it a major cause of illnesses and deaths in people who consume it [1]. These diseases result from the pathogenic microorganism presence in water, classified into three groups: bacteria, virus, and protozoan. Therefore, different methods of water purification have evolved simultaneously with studies of these microorganism, highlighting the Chlorination as the most used water purifying form in the world [1]-[3]. However,

Manuscript received November 01, 2015; revised February 02, 2016; accepted March 08, 2016. Date of publication March 31, 2016; date of current version July 08, 2016. This work was supported in part by CAPES, in part by CNPq, and in part by FAPESP, Brazilian R\&D agencies.

The authors are with the Power Electronics Laboratory-LEP, Electrical Engineering Department, Sao Paulo State University, Ilha Solteira 15385-000, Brazil (e-mail: Ideoroa@gmail.com; guiamelo@gmail.com; canesin@dee.feis.unesp.br).

Color versions of one or more of the figures in this paper are available online at http://ieeexplore.ieee.org

Digital Object Identifier 10.1109/TIE.2016.2549500 researches ensure that this method contributes to potentially carcinogenic compound formations known as trihalomethanes [4]-[7]. Therefore, the use of UV light as a water disinfection mechanism is a very interesting method, because it ensures the pathogenic microorganism inactivation, and it avoids the hazardous substance formation to public health by substituting the chemical substance usage. Equivalent to a chemical concentration in water for it to be purified, the UV radiation dosage is the main parameter in bacterial inactivation process. Therefore, there is a need to apply one methodology that ensures the achievement of the ideal UV dose value, which is the main purpose of this paper for a drinking water purifier application.

The main motivation comes from analysis developed at the Power Electronics Laboratory (LEP), UNESP (Ilha Solteira-SP, Brazil), where a commercial water purifier equipped with an electronic ballast to activate just one UV lamp (a low-pressure mercury lamp, model T5 6W General Electric), was tested and the germicidal effect from UV radiation was verified. Comparing the fecal coliforms amount from a water sample, before and after the UV process, the inactivated microorganisms portion that was found resulted in an inappropriate purifying process, not allowing human consumption of the purified water sample.

Therefore, this paper investigates the correct UV radiation amount (UV dose), using a multiple segment summation source (MSSS) T5 UV lamp model, combined with hydraulic water flux improvements for a proposed prototype, in order to comply with the NSF/ANSI Standard 55, considering residential and commercial water purifier applications.

\section{A. Ultraviolet Light and its Germicidal Action}

Ultraviolet radiation corresponds to an electromagnetic spectrum limited band of light, which correspond to wavelengths between 100 and $400 \mathrm{~nm}$ [2], [3], [8]. Within this region, there is a range known as UV-C, or germicidal, which is easily absorbed by proteins (DNA and RNA) causing mutations and/or cell death, this is a very interesting fact for microorganisms inactivation in drinking water applications [1]-[3], [8]. Studies confirm that the wavelength at the peak light proteins absorption is given around $260 \mathrm{~nm}$, when the microorganism DNA structure links are separated by the radiation, leading to formation of dimers, which at the DNA tape reading process time inhibits its metabolism and stops the cell replication [1]-[3], [8].

\section{B. UV Lamps}

Several UV light source technologies have been developed and can be applied for drinking water application, such as 
mercury lamps, metal halide, xenon, deep UV LED, among others. However, the best option in regard to purification processes with UV light lamps is the low-pressure mercury ones, owing to their current cost, great validation at researches and UV light purifier products [3], [9]. The UV low-pressure mercury lamp is, therefore, applied to this study, considering that more than $95 \%$ of its total UV ray emission is around 253.7-nm wavelength, which is good for microorganisms inactivation [1]-[3], [8], and because it has great similarity to the fluorescent lamps, differing only by a phosphor layer coated to the glass bulb, allowing the usage of T5-6 W fluorescent lamp model already developed in [10]. As mentioned, the UV lamps have the same electrical behavior to conventional fluorescent lamps, what characterize the two well-known operation stages: preheating and steady state.

1) Preheating Stage: The UV lamp in the preheating stage behaves like a high impedance, where the only current flowing through the gas column is the glow current, which is very small in magnitude and can be neglected. However, the lamp filament temperature levels are limited by the relationship between the filament resistance at room temperature, $R_{C}$, and the filament resistance at heating temperature, $R_{H}$, as given by

$$
T_{H}=T_{C}\left(\frac{R_{H}}{R_{C}}\right)^{0.814}
$$

where $T_{H}$ is the heating temperature $\left(700{ }^{\circ} \mathrm{C}-1000{ }^{\circ} \mathrm{C}\right)$ and $T_{C}$ is the ambient (room) temperature. Thus, in view of the temperature range suggested by [10], the relation between $R_{H}$ and $R_{C}$ is defined as

$$
4.28<\frac{R_{H}}{R_{C}}<6.25
$$

In addition to the relationship established in (2), it is also necessary that the filament preheating is done over a minimum time, for which ANSI C82.1-1985 and ANSI C82.11-1993 define the minimum time in $500 \mathrm{~ms}$, without establishing a maximum time [10].

2) Steady State: For this case, the lamp behaves like a variable resistor, and the selected model for this application is governed by a fourth degree equation, considering it can reproduce the lamp dynamic behavior [11]. This model is based on different sets of experimental data obtained by oscillograph analysis, where the parameters depend on the room temperature, as given by (3), and the lamp power processed is controlled by the switching frequency.

$$
\begin{aligned}
V_{l}\left(P_{l}, T\right)=V_{0}(T)+V_{1}(T) P_{l} & +V_{2}(T) P_{l}^{2}+ \\
& +V_{3}(T) P_{l}^{3}+V_{4}(T) P_{l}^{4} .
\end{aligned}
$$

The aforementioned equation model can easily reach the equivalent resistance (4), which provides the ballast design for mercury vapor lamps using some methodology and also is a great solution to predict the light behavior in dimerization use for any operation given point [12]

$$
R_{l}\left(P_{l}, T\right)=\frac{V_{l}\left(P_{l}, T\right)^{2}}{P_{l}}
$$

where $V_{l}$ is the RMS value of voltage over the fluorescent lamp as a function of $P_{l} ; P_{l}$ is the value of power processed through gas column of the fluorescent lamp (without considering the filaments); and $T$ is the ambient (room) temperature [for (3) and (4)] [12].

\section{UV Dose}

The UV dose is the most important parameter for the UV light purifier design, once it sets the minimum power required to inhibit the reproduction and metabolism functions of different bacteria and viruses present in the unpurified water. It means that the UV dose is equivalent to an amount of some chemicals concentration $(\mathrm{mg} / \mathrm{L})$ acting as a given standard for water disinfection process [2].

The UV dose received by a particle into the UV filter chamber is defined as the product of UV light intensity, $I_{\mathrm{UV}}$, provided by the source station and the particle time exposure, $t_{\exp }$, as given by

$$
D_{\mathrm{UV}}=I_{\mathrm{Uv}} t_{\exp } .
$$

The UV doses required to inactivate one microorganism differ according to their specific UV light resistance. In this paper, the limits recommended by NSF/ANSI 55 standard are considered [13]. First, assuming residential and commercial applications, where the water has been subjected to previous decontamination process, as class B devices $\left(16 \mathrm{~mJ} / \mathrm{cm}^{2}\right)$. Furthermore, for the class A devices case $\left(40 \mathrm{~mJ} / \mathrm{cm}^{2}\right)$, it will be considered those commercial applications with necessity of highly quality purified water (pharmaceutical, medical applications, etc.) [3], [13].

\section{PURIFyING StRUCtURE}

Considering the water purifier structure employing UV radiation project, hydraulic and optic behaviors are essential, where an accurate mechanical model is required for previous analysis. Thus, two CAD mechanical models for UV purifier, developed in Solidworks, are presented for comparative analysis, where the first one was obtained to a commercial purifier and the second one corresponds to a multilamp UV proposed purifier, developed for comparative laboratory analysis and presented in this paper.

In the UV dose analysis by simulation, a methodology developed by [14] and named three-step UV fluency rate and fluid dynamics (TURF) was employed. The TURF methodology, different from others, allows a separate fluid dynamics analysis from UV radiation one, saving computational effort and reaching the same accuracy. The hydraulic analysis was performed by Solidworks Flow Simulation, using the purifier mechanical structure previously developed for UV exposure time determination, and UV dose was calculated for relevant equations by means of MATLAB routine.

\section{A. Commercial Structure Mechanical Characteristics}

The commercial water purifier, admitted for this study, has only one immerse UV purifier chamber, which is located within a larger chamber, filed with water. In this structure, a prepurifier conventional filter stage is integrated, and after passing through 


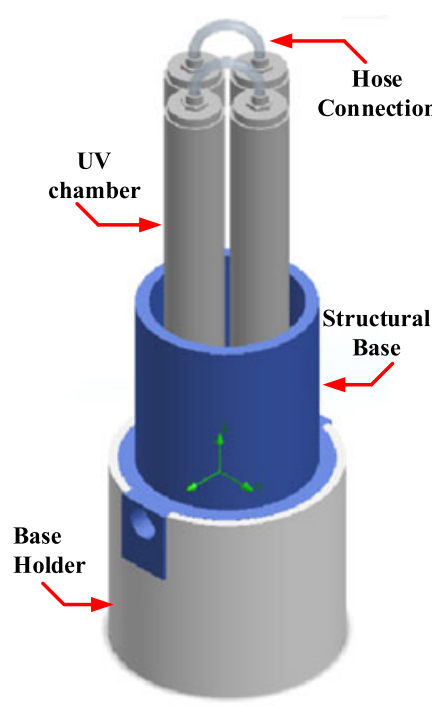

(a)

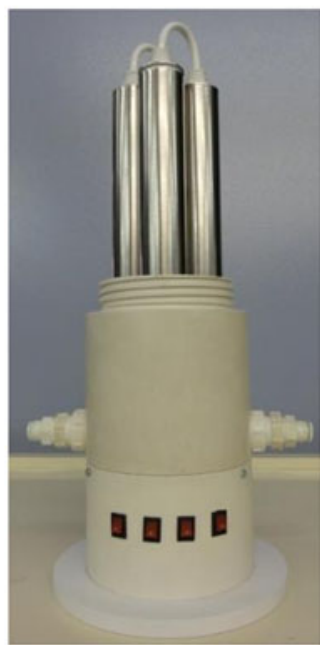

(b)
Fig. 1. Proposed water purifier structure (a) CAD Design, (b) Prototype.

this prepurifier stage, the water is stored within the second stage, flowing through the UV chamber itself when the water level reaches a stainless steel tube apex.

\section{B. Proposal Structure Mechanical Characteristics}

The proposed structure for an adequate purification by UV action was designed using modular pieces for easy assembly, maintenance, and parts support, as shown in Fig. 1. Obviously, as cited before, the purifier must give the adequate UV dose for water microorganism inactivation. Thus, in order to attend this requirement, the proposed prototype was designed to contain up to four UV chambers, in order to test different arrangements for UV lamps (different nominal electrical powers) and UV exposure times.

Thus, the developed and implemented prototype shown in Fig. 1, designed using Solidworks, allows the optimized solution for NSF/ANSI 55 in both purifier classes, A and B, by using UV lamps T5 model with different electric powers $(4,6,8$, and $11 \mathrm{~W})$.

As visualized in Fig. 1, the purifier is composed of four independent chambers, where the water receives a given UV dose when flowing through it. Each UV chamber is attached to a piece named structural base, which adds water entrance, water exit, and a connection between two chamber functions. In the same figure, two little hoses for chamber connection can be observed, as well the base holder for lamp resonant filter circuitry.

Fig. 2 shows the UV chamber pieces in details. It is possible to see that this water purifier is a closed-channel UV system [15], [16], wherein the water flow is forced into UV lamp proximity, passing through the four UV purifier chambers, in a sequence illustrated by Fig. 3 .

\section{Hydraulic Behavior}

The hydraulic behavior depicts the necessary time for a particle to flow through chambers. In this context, Solidworks Flow

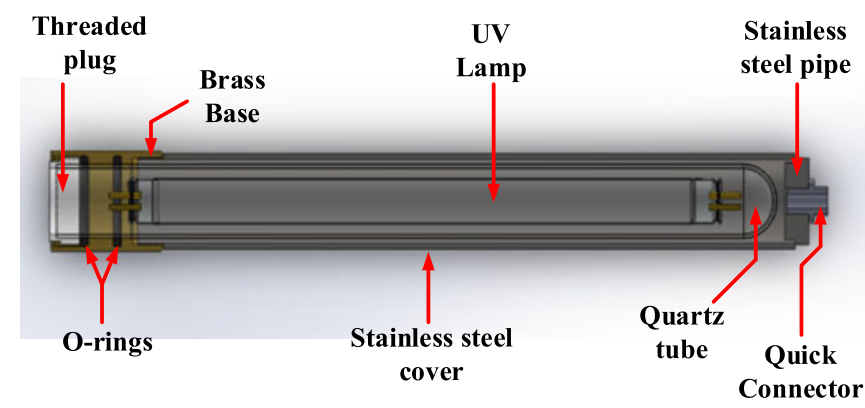

Fig. 2. Proposed purifier chamber structure.

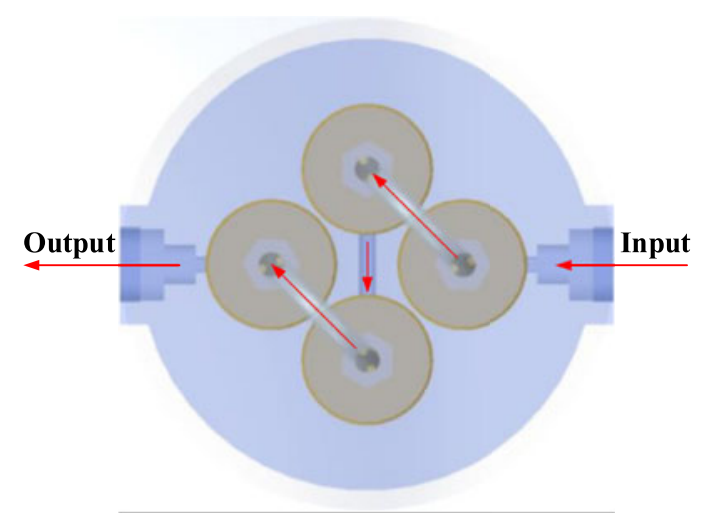

Fig. 3. Water path for the proposed purifier structure.

Simulation software was used for analysis, allowing a detailed investigation in liquid behavior dynamics, and therefore, determining the particle UV radiation exposure time for each particle. In order to obtain the experimental comparisons, the proposed water purifier used the same flow rate $\left(15 \mathrm{~cm}^{3} / \mathrm{s}\right)$ as the commercial one, defined by water column pressure and the system minimum cross-sectional area.

In this context, Fig. 4 shows the particle trajectories and its velocities through entire purifier system, Fig. 4(a) commercial structure and Fig. 4(b) proposed structure, where velocity variations are imposed for smaller cross section of UV chamber connection ducts, input and output, what brings some turbulence to the UV chamber effective area. The connection tube cross-sectional areas for the proposed prototype are decreased intentionally, in order to minimize the dead zone times between effective UV radiation zones. The key aspect in this study is the relatively constant water velocity characteristic through the UV chambers, what can be active more effectively by some physical modifications in the prototype design.

The turbulence phenomenon occurs in order to a right angle between entrance ducts and chamber channel connections. The particle UV radiation exposure times, for both purifiers, are calculated through velocity versus distance graphics, what are done for different lamp's power for the proposed purifier structure, whose lamp lengths diverge for each case, as presented in Table I. Obviously, the particle UV radiation exposure time for the proposed purifier is much larger than the same parameter for the commercial purifier, once four series lamps are mounted in proposed one, which reaches UV dose directly. 


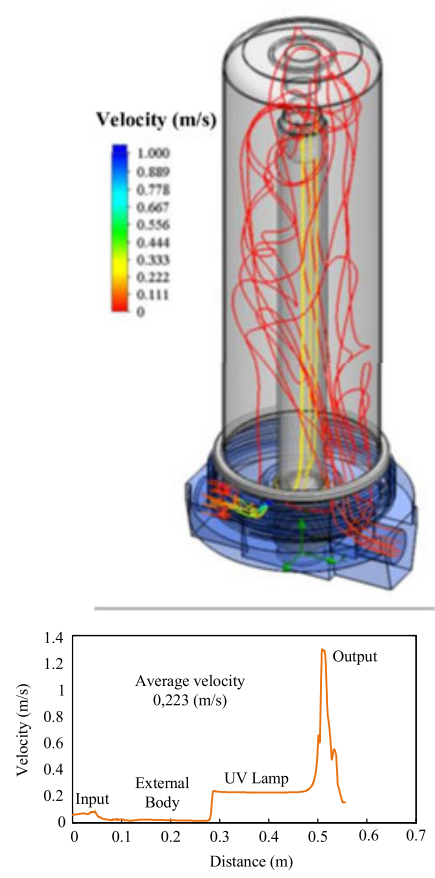

(a)

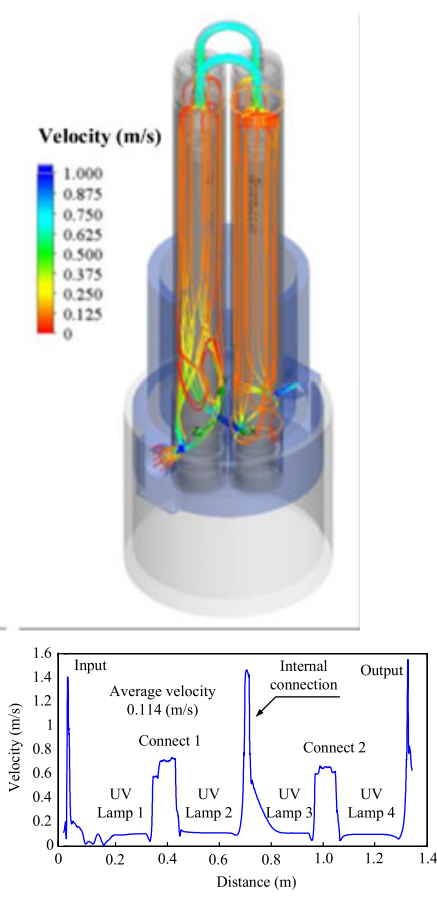

(b)
Fig. 4. Water flux behavior within the purifiers (a) Commercial UV purifier, (b) Proposed UV purifier prototype.

TABLE I

EXPOSURE TIMES TO UV RADIATION

\begin{tabular}{lccc}
\hline \hline Lamp type & Length (m) & $\begin{array}{c}\text { Exp. Time Commercial } \\
\text { Purifier (s) }\end{array}$ & Exp. Time Proposed Purifier (s) \\
\hline $4 \mathrm{~W}$ & 0.12 & - & 3.085 \\
$6 \mathrm{~W}$ & 0.19 & 0.841 & 4.884 \\
$8 \mathrm{~W}$ & 0.26 & - & 6.684 \\
$11 \mathrm{~W}$ & 0.15 & - & 3.856 \\
\hline \hline
\end{tabular}

\section{Optical Behavior}

In order to compute the UV dose, considering tubular UV lamp radiation analysis, the MSSS model was employed. As reported by [15], the MSSS mathematical model presents compatible accuracy among the best optical models, but considerably lower computational efforts. Fig. 5 illustrates, in easy way, the UV radiation behavior when the UV radiation travels through different materials, assisting the MSSS model understanding for the UV chamber.

The UV ray arrives from the source with $\theta_{1}$ angle and passes through three different materials until reaches the water particle, which travels through the chamber in a known trajectory. Modifications in UV radiation incidence angles are caused by refraction coefficient changes in material boundaries, additionally resulting in some energy loss in order to partial radiation reflection. The three different materials presented in Fig. 5 are, respectively, air, quartz glass, and water, which are related to the following parameters:

1) $r_{1}$ : radius from the lamp center to quartz tube inner wall;

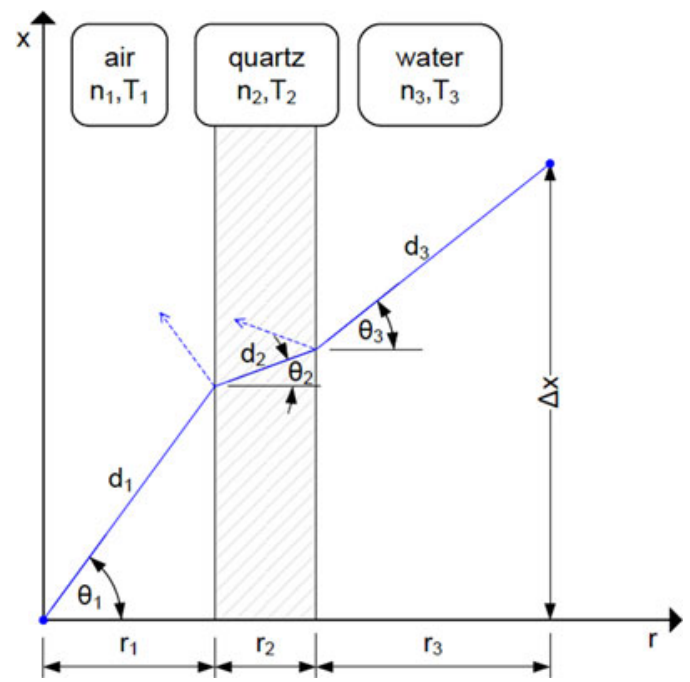

Fig. 5. UV radiation behavior for a purification chamber [15].

2) $r_{2}$ : quartz tube thickness;

3) $r_{3}$ : radius from the lamp center to quartz tube inner wall;

4) $\Delta x$ :axial dimension related to radiation ray origin and the particle, considering only the longitudinal axis, parallel to the lamp;

5) $\theta_{i}$ : refraction angle in each material;

6) $d_{i}$ : straight path dimension for UV ray for each material;

7) $n_{i}:$ refractive index in each material.

The MSSS model considers the lamp, by definition, as a group of $N$ cylindrical source segments, equally spaced, where the radiation vector is a normal vector angle cosine function, decreasing when the refraction angle, $\theta_{1}$, becomes larger. Consequently, each output cylindrical modeled source power is the lamp total power divided by $N$, considering the interested wavelength [15], [17]. The UV radiation delivered to one particle is the sum of UV radiation contributions of all segmented sources, which will depend on each source UV ray path and material incidence angles, defining the refraction angle, reflection angle, and absorbance in each distinct material boundary, which in addition, will be affected by the focus effect, as defined in the following equation:

$$
\begin{array}{r}
I_{\mathrm{UV}}=\sum_{n=1}^{N} \frac{\Phi / N}{4 \pi\left(d_{1}+d_{2}+d_{3}\right)^{2}}\left(1-R_{12}\right)\left(1-R_{23}\right) \\
\cdot T_{2}^{d_{2} / 0.01} T_{3}^{d_{3} / 0.01} \cos \left(\theta_{1}\right) \text { Focus. }
\end{array}
$$

where $R_{12}$ is the reflectance between air and quartz, and $R_{23}$ is the reflectance between quartz and water, both defined in [8]; $T_{2}$ and $T_{3}$ are the transmittance of quartz and water, respectively. Focus factor is depicted as

$$
\text { Focus }=\frac{\frac{\left(d_{1}+d_{2}+d_{3}\right)^{2}}{\left(r_{1}+r_{2}+r_{3}\right) \cos \left(\theta_{3}\right) n_{1}}}{\frac{r_{1}}{n_{1} \cos ^{3}\left(\theta_{1}\right)}+\frac{r_{2}}{n_{2} \cos ^{3}\left(\theta_{2}\right)}+\frac{r_{3}}{n_{3} \cos ^{3}\left(\theta_{3}\right)}} .
$$

Table II presents some parameters for UV radiation calculus determination using an MSSS model, where refraction and transmittance indexes were collected from [15], and radius 
TABLE II

Optical PARAmeters

\begin{tabular}{llccc}
\hline \hline Medium & $\begin{array}{c}\text { Refraction } \\
\text { Index }\end{array}$ & Transmittance & $\begin{array}{c}\text { Commercial } \\
\text { Purifier [mm] }\end{array}$ & $\begin{array}{c}\text { Proposed } \\
\text { Purifier [mm] }\end{array}$ \\
\hline Air & $n_{1}=1.000$ & $T_{1}=1.0000$ & $r_{1}=9$ & $r_{1}=10.50$ \\
Quartz & $n_{2}=1.506$ & $T_{2}=0.8208$ & $r_{2}=1$ & $r_{2}=1.75$ \\
Water & $n_{3}=1.376$ & $T_{3}=0.8000$ & $r_{3}=2$ & $r_{3}=1.60$ \\
\hline \hline
\end{tabular}

TABLE III

CHARACTERISTICS OF LAMPS

\begin{tabular}{lccc}
\hline \hline Lamp Type & Length (m) & UV254nm Power (W) & Efficacy (\%) \\
\hline $4 \mathrm{~W}$ & 0.12 & 0.9 & 22.50 \\
$6 \mathrm{~W}$ & 0.19 & 1.7 & 28.33 \\
$8 \mathrm{~W}$ & 0.26 & 2.4 & 30.00 \\
$11 \mathrm{~W}$ & 0.15 & 2.7 & 24.55 \\
\hline \hline
\end{tabular}

TABLE IV

UV RADIATION AND UV DOSE, CONSIDERING $Q=15 \mathrm{~cm}^{3} / \mathrm{s}$

\begin{tabular}{lcccc}
\hline \hline Lamp Type & $\begin{array}{c}I_{\mathrm{UV}_{\mathrm{MSSS}}} \\
\text { Commercial } \\
{\left[\mathrm{mW} / \mathrm{cm}^{2}\right]}\end{array}$ & $\begin{array}{c}I_{\mathrm{UV}} \mathrm{MSSS} \\
\text { Proposed } \\
{\left[\mathrm{mW} / \mathrm{cm}^{2}\right]}\end{array}$ & $\begin{array}{c}\text { UV Dose } \\
\text { Commercial } \\
{\left[\mathrm{mJ} / \mathrm{cm}^{2}\right]}\end{array}$ & $\begin{array}{c}\text { UV Dose } \\
\text { Proposed } \\
{\left[\mathrm{mJ} / \mathrm{cm}^{2}\right]}\end{array}$ \\
\hline $4 \mathrm{~W}$ & - & 6.0 & - & 18.51 \\
$6 \mathrm{~W}$ & 8.6 & 7.3 & 6.94 & 35.65 \\
$8 \mathrm{~W}$ & - & 7.6 & - & 50.80 \\
$11 \mathrm{~W}$ & - & 14.5 & - & 55.91 \\
\hline \hline
\end{tabular}

dimensions were obtained from CAD developed model for both purifiers (commercial and proposed structures).

According to the Table II data, it is important to clarify that radius dimension sum represents the stainless steel inner wall distance from radiation source, which is the farthest water point from the source, resulting in lower radiation intensity for a particle located there, and then, considering the worst case for microorganism deactivation through UV radiation.

Table III complements the remaining information for UV lamps used, collected from [18], allowing the UV intensity simulation development for the systems, where the selected lamps with different power can be employed.

Table IV shows a better UV radiation intensity average from the commercial purifier chamber, equipped with a $6-\mathrm{W} \mathrm{UV}$ lamp, which, as can be confirmed from Table II, is owing to the distance from radiation source to the inner wall of the stainless steel tube (the dimension sum of $r_{1}, r_{2}$, and $r_{3}$ ) and the quartz thickness are bigger in the proposed purifier chamber case, 1.85 and $0.75 \mathrm{~mm}$, respectively, resulting in higher losses. It should be remember that the proposed purifier has up to four chambers and higher UV exposure time values.

Furthermore, for UV dose calculation, the water flow rate $(Q)$ is considered with a negligible turbulence level, allowing an average velocity determination for particles, which results in an average exposure time value. Therefore, the UV dose is obtained by multiplying the UV radiation intensity average
TABLE V

FLOW REQUIRED $Q\left(\mathrm{CM}^{3} / \mathrm{s}\right)$

\begin{tabular}{lcc}
\hline \hline Lamp Type & Class B & Class A \\
\hline $4 \mathrm{~W}$ & 17.4 & 6.9 \\
$6 \mathrm{~W}$ & 33.4 & 13.4 \\
$8 \mathrm{~W}$ & 47.6 & 19.1 \\
$11 \mathrm{~W}$ & 52.4 & 20.9 \\
\hline \hline
\end{tabular}

value, presented in Table IV, with the exposure time value, as given by Table I.

Therefore, analyzing UV dose results in Table IV, the disagreement with the minimum required UV dose for water pathogen microorganism deactivation is evident, when confronted with NSF/ANSI 55 standard [13], for the commercial water purifier employed in this study. However, for the proposed purifier case, the UV dose is superior to the minimum value established by class B purifiers $\left(16 \mathrm{~mJ} / \mathrm{cm}^{2}\right)$, making the 4-W lamps application a good choice for energy save and compact design. In addition, for different lamp power arrangements, 8- and 11-W versions met the requirements for class A purifiers $\left(40 \mathrm{~mJ} / \mathrm{cm}^{2}\right)$, and the $6-\mathrm{W}$ version could achieve the standard limits, for class A, with some prototype improvements or water flux control.

In this context, (5) can be rewritten in terms of UV intensity, chamber volume, and water flow rate, resulting in

$$
D_{\mathrm{UV}}=I_{\mathrm{Uv}} t_{\mathrm{exp}}=I_{\mathrm{UV}} \frac{\mathrm{Vol}}{Q} .
$$

where, Vol is the water volume stored in UV chambers and $Q$ is the water flow for purification process.

Then, considering none design modifications for the proposed purifier, and using (8), it is possible to define the required water flow rate for each standard classification compliance, as shown in Table V.

Through Table V data, it is observed that 4-W lamp version for proposed purifier is adequate for class-B devices, where the base value for flow rate is $12.5 \mathrm{~cm}^{3} / \mathrm{s}$, filling a $250-\mathrm{ml}$ glass in $20 \mathrm{~s}$. In addition, to obtain class-A device satisfactoriness, the minimum necessary power lamp version is the 6-W one, which can be employed in class B version too. Finally, the 8- and 11-W lamp versions can be employed for class-A devices, where water flow rate could be calibrated for better performance according to consumer goal.

\section{Electronic BaLLASt FOR UV LAMPS}

In Fig. 6 is illustrated a simplified schematic of the electronic ballast developed in this study, which keeps the same general ballast structure presented in [19]. However, in this case, a highpower factor (HPF) flyback rectifier is used as input stage for supplying the inverter stage, which is a conventional half bridge with four series-resonant parallel-loaded (SRPL) filters [12].

In this case, the current balance in the multiple UV lamps is achieved, according to [19], ensuring low variations in the Flyback rectifier output voltage, a half-bridge inverter stable switching frequency, and filters elements and lamps with low 


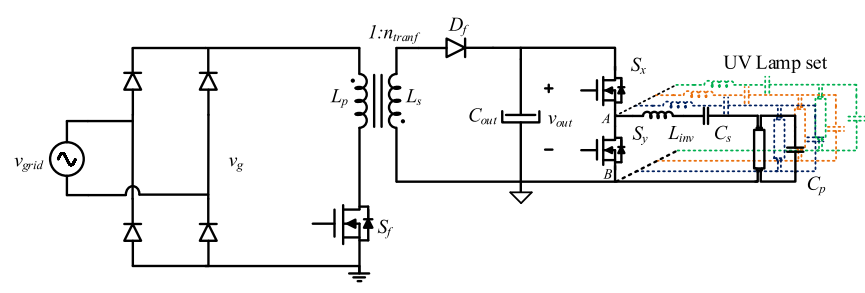

Fig. 6. Simplified schematic of developed electronic ballast.

TABLE VI

INPUT AND OUtPut DATA For the PROPOSED Electronic BaLLast

\begin{tabular}{lcc}
\hline \hline Parameter & Symbol & Value \\
\hline RMS input voltage value & $V_{\text {in rms }}$ & $90-240 \mathrm{~V}$ \\
Flyback rectifier output voltage & $V_{\text {out }}$ & $240 \mathrm{~V}$ \\
Flyback rectifier output voltage ripple & $\Delta V_{\text {out }}$ & $5 \%$ \\
Flyback rectifier output power & $P_{\text {out }}$ & $44 \mathrm{~W}$ \\
Flyback rectifier switching frequency & $f_{f}$ & $30 \mathrm{kHz}$ \\
Flyback rectifier efficiency & $\eta$ & 0.8 \\
AC system frequency & $f_{\mathrm{grid}}$ & $60 \mathrm{~Hz}$ \\
Minimum preheating time & - & $500 \mathrm{~ms}$ \\
Ambient temperature & $T$ & $25^{\circ} \mathrm{C}$ \\
\hline
\end{tabular}

TABLE VII

Design Parameters for the HPF Flyback Rectifier

\begin{tabular}{lcc}
\hline \hline Parameter & Symbol & Value \\
\hline Transforming ratio & $n_{\operatorname{tranf}}$ & 1 \\
Maximum voltage gain ratio & $\beta$ & 1.89 \\
Duty cycle (Adopted) & $D$ & 0.45 \\
Primary inductance & $L_{p}$ & $500 \mu \mathrm{H}$ \\
Secondary inductance & $L_{s}$ & $500 \mu \mathrm{H}$ \\
Output capacitance & $C_{\text {out }}$ & $47 \mu \mathrm{F}$ \\
\hline \hline
\end{tabular}

parametric variations, which makes a control strategy for these currents unrequired.

According to the proposed purifier, an electronic ballast to feed four UV lamps is presented. A brief design of the proposed electronic ballast is presented as follows. This design uses the parameters summarized in Tables VI and VII.

\section{A. HPF Flyback Rectifier}

The flyback converter is one of the most popular power electronic converter for supplying loads below $150 \mathrm{~W}$ and it presents a simple circuit configuration and a reduced number of components [20], [21]. The main reason for the selection of this structure was its capability to obtain adjustable voltage gain (step-up/-down voltage gains), besides the high input power factor (HPF) provided by the Flyback rectifier stage in DCM, where it presents good dynamic and good transient response, in relation to HPF boost rectifier structure [9]. Moreover, this converter gives additional advantage such as voltage isolation between power supply and loads, offering enhanced safety and improving noise immunity.
The main equations used in the design of this rectifier are summarized as follows:

$$
\begin{aligned}
\beta & =n_{\text {tranf }} \frac{V_{\text {out }}}{V_{\text {in(peak })}} \\
D & =\frac{t_{\text {on }}}{T_{\text {flyback }}}<\frac{\beta}{1+\beta} \\
L_{p} & =\frac{\eta V_{\text {in }(\text { peak })}^{2}}{4 f_{f} P_{\text {out }}} D^{2} \\
L_{s} & =L_{p} n_{\text {tranf }}^{2} \\
C_{\text {out }} & \geq \frac{P_{\text {out }}}{2 f_{\text {grid }}\left[\left(V_{\text {out }}+\Delta V_{\text {out }}\right)^{2}-\left(V_{\text {out }}-\Delta V_{\text {out }}\right)^{2}\right]} .
\end{aligned}
$$

The constraint related with the duty cycle $D$ of the PWM signal for the switching of the transistor $S_{f}$, represented in (10), ensures the flyback rectifier operates in DCM.

Then, HPF flyback rectifier parameters are calculated according to (9) until (13), and using the data from Table VI, resulting the data summarized in Table VII.

\section{B. Half-Bridge-Type Inverter With SRPL Filter}

In order to design the inverter stage, a half-bridge inverter with SRPL filters, is adopted the methodology proposed in [12]. In this way, it is adopted the UV lamp model based on the fluorescent lamp model developed in [11]. Thereby, an electronic ballast for operating in preheating and steady-state process was designed.

Then, the SRPL-filter parameters are calculated according to [12] and [19] using the data illustrated in Table VI, and for the T5-8 W UV lamp case, the values of $C_{s}$ and $C_{p}$ are adopted in order to obey the relation $C_{s p}>25$ [12], [19].

$$
C_{s}=180 \mathrm{nF}, \quad C_{p}=6.8 \mathrm{nF} .
$$

Finally, it is possible to obtain values of $f_{\text {ign }}$ and $L_{\text {inv }}$.

$$
f_{\text {ign }}=0.897, \quad L_{\text {inv }}=2.63 \mathrm{mH} .
$$

Then, a closed-loop control is implemented in order to maintain an output voltage $V_{\text {out }}$ around 240VDC, this control was developed on a TMS320F28027 microcontroller, which in besides defining the control signal to the flyback rectifier, it also sets the half-bridge-inverter switching frequency. It should be observed that this dc value for $V_{\text {out }}$ was maintaining in accordance with the commercial purifier, in spite of the low rms voltage value for the used UV lamps (near to $30 \mathrm{~V}$ ). This fact will affect the losses in the resonant tank filter, and in the overall circuitry. Thus, using the proposed flyback rectifier, this dc voltage value could be adapted for a better efficiency and energy saving. However, in order to establish the same conditions for the experimental comparisons between the commercial and proposed purifiers, this high de voltage value was sustained in this study.

As mentioned, it is implemented the half-bridge inverter control together with the flyback controller on the microcontroller. This way, it is adopted the ignition methodology for multiple lamps presented in [19]. After the preheating time (at least 


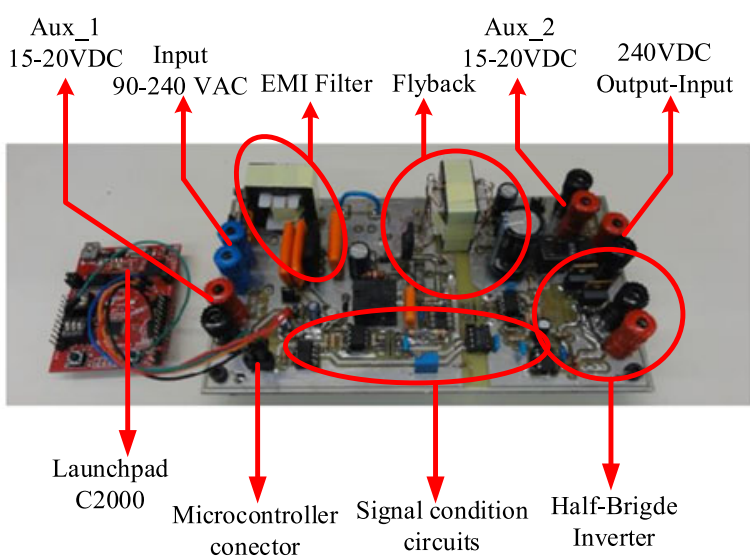

(a)

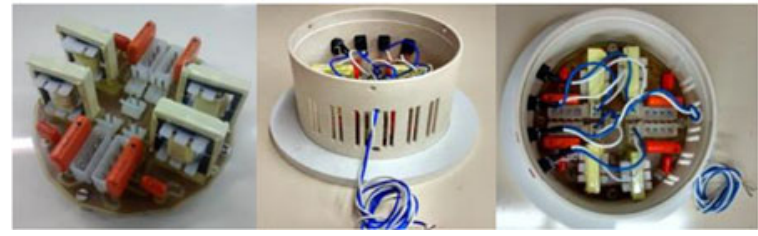

(b)

Fig. 7. Photographs of the implemented ballast (a) Flyback rectifier and Half-Bridge inverter stages, (b) SRPL filters set.

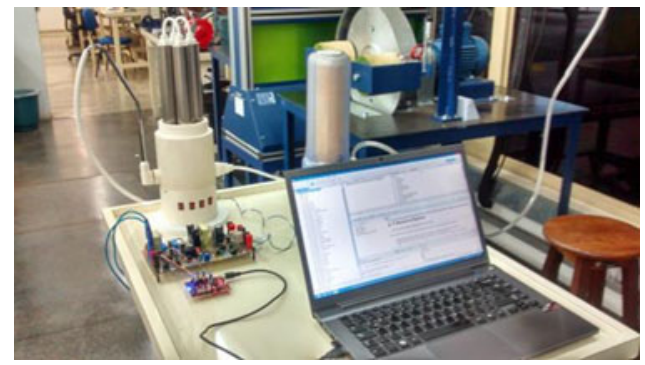

Fig. 8. Test mounting, laboratorial setup, for water purification process with the proposed purifier.

$500 \mathrm{~ms}$ ), the switching frequency of the half-bridge inverter is modified toward the filter resonance frequency, in order to impose a high-voltage value to the lamps, creating current flow through the gas column of the lamp.

In Fig. 7(a) is shown the implemented prototype photograph, where the flyback rectifier and the half-bridge inverter (without of the SRPL-filters set) stages are built-in. The SRPL filters implemented set is presented in Fig. 7(b), which is located into the base holder of the proposed purifier, as shown in Fig. 1.

\section{EXPERIMENTAL RESULtS}

Fig. 8 shows the complete assembly details, experimental setup, for water purification process tests, using the purifying structure proposed and implemented. In this way, water flow is set at $12.5 \mathrm{~cm}^{3} / \mathrm{s}$, whose pressure does not interfere with the behavior of water flow through the purifier. It should be informed that this water flow was sustained for all experimental comparisons between the commercial and proposed purifiers. The main

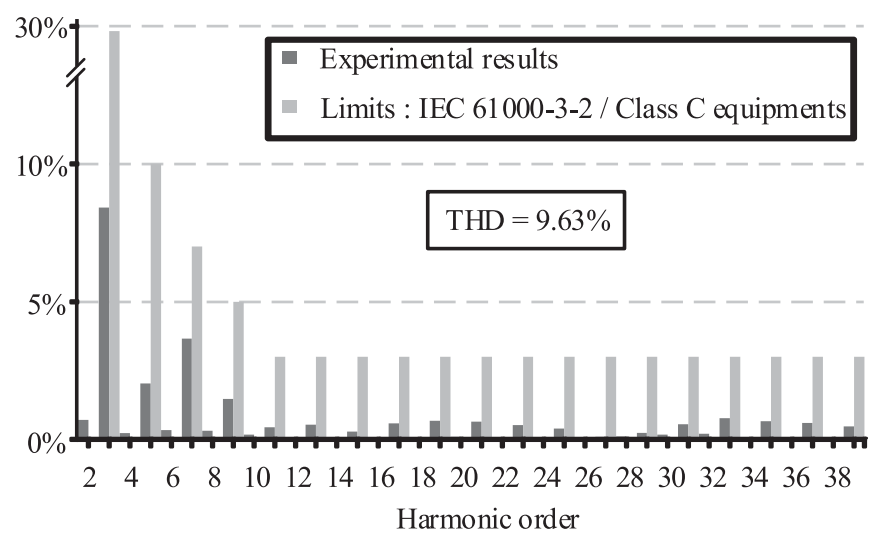

Fig. 9. Frequency spectra of the input current.

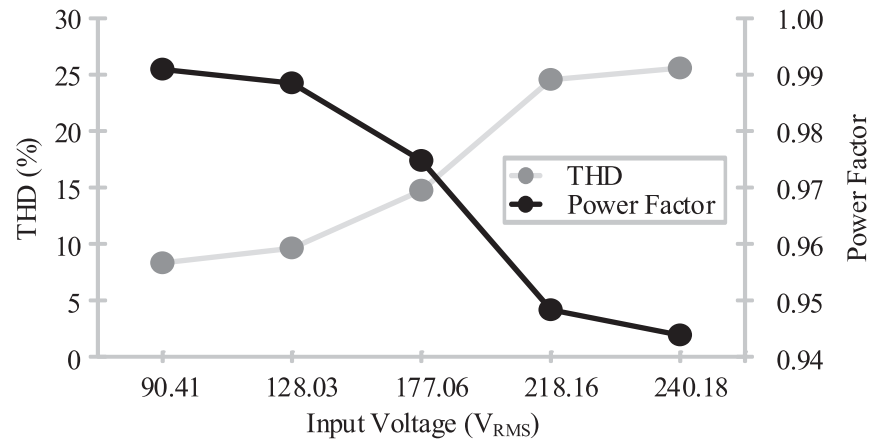

Fig. 10. THD and power factor versus $V_{\mathrm{in}}$.

experimental results for the proposed electronic-ballast and the germicidal action for the purifier proposed are presented as follows.

\section{A. Electronic Ballast}

In this paper, only tests for water purification process, when the proposed purifier was equipped with $8-\mathrm{W}$ and $6-\mathrm{W}$ UV lamps, are presented. However, the experimental results concerning the electronic-ballast behavior are limited to 8-W UV lamps case and illustrated as follows.

The IEC 61000-3-2 standards for class-C devices was used in this paper in order to compare the experimental results, due to the absence of a specific standard for this application (water purifier). Furthermore, considering the low nominal active power for the application (near to $40 \mathrm{~W}$ ), the limits imposed by the IEC 61000-3-2 for Class A devices are easily accomplished for the proposed water purifier. Therefore, the frequency spectra of the input current measured is compared with IEC 61000-3-2 standards for class-C equipments. In Fig. 9 is shown every limit imposed by this standard are attended. Additionally, in Fig. 10, power factor and THD values are shown for different rms input voltage values. Thus, every limits imposed by IEC 61000-3-2 for Class-C devices are attended for each operating point.

The input voltage and input current waveforms measured in the electronic ballast are presented in Fig. 11. It is shown that the phase shift between the input voltage and input current is negligible and a HPF is ensured with the THD values illustrated 


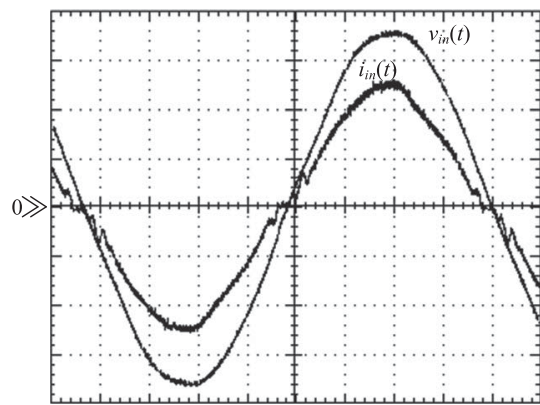

$v_{i n}(t): 50 \mathrm{~V} / \mathrm{div} ; 2 \mathrm{~ms} / \mathrm{div}$ $i_{\text {in }}(t): 200 \mathrm{~mA} / \mathrm{div} ; 2 \mathrm{~ms} / \mathrm{div}$

(a)

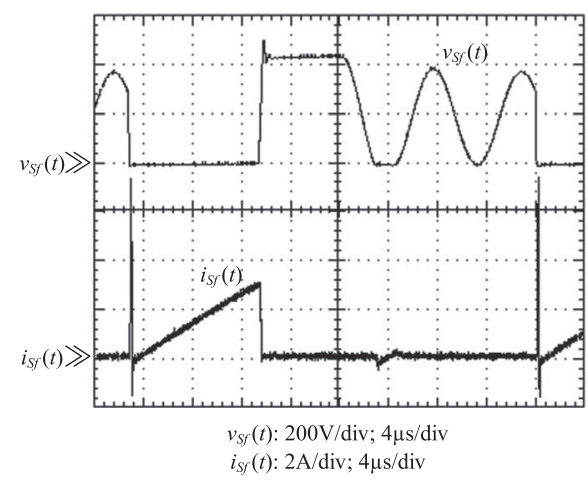

(b)

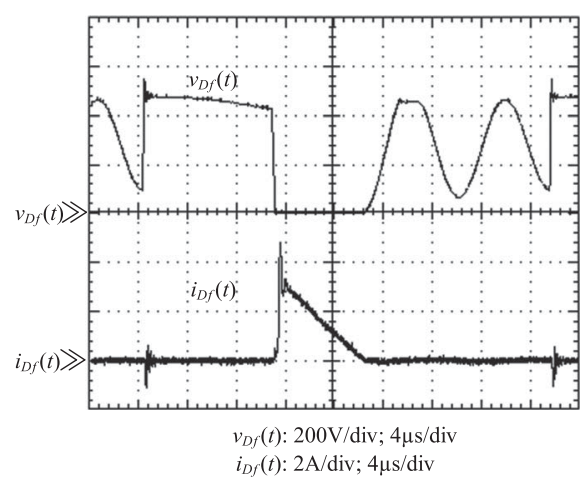

(c)

Fig. 11. (a) Input voltage and current waveforms of the implemented electronic ballast, 8-W UV lamps. Voltage and current waveforms of: (b) $S_{f}$ and (c) $D_{f}$.

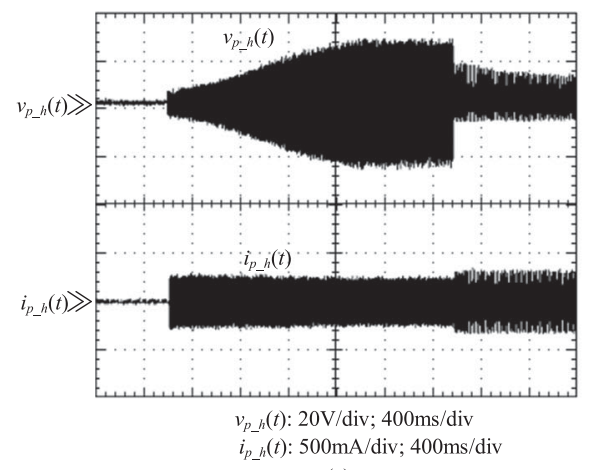

(a)

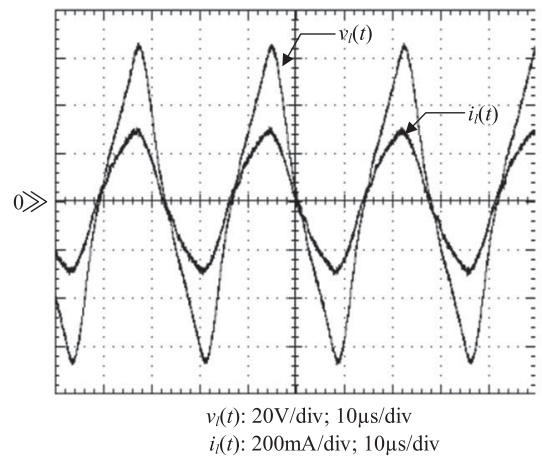

(b)

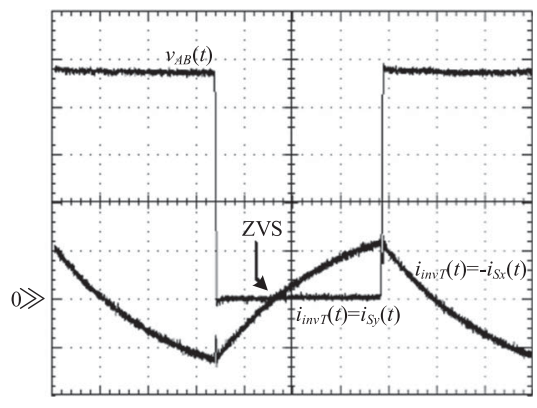

$v_{A B}(t): 50 \mathrm{~V} / \mathrm{div} ; 4 \mu \mathrm{s} / \mathrm{div}$ $i_{\text {inv }}(t): 1 \mathrm{~A} / \mathrm{div} ; 4 \mu \mathrm{s} / \mathrm{div}$

(c)

Fig. 12. (a) Voltage and current through one lamp in preheating state, (b) voltage and current waveform for one lamp operating in steady state, (c) output voltage and output current waveform of the half-bridge inverter stage, operating in steady state; 8-W UV lamp.

in Fig. 9. In this way, when the UV lamp set operates in steady state, a power factor of approximately 0.988 is measured for this operating point.

In Fig. 11(b) and (c) are shown voltage and current waveforms of $S_{f}$ and $D_{f}$ during one commutation period when the bacterial inactivation process with the 8 -W UV lamp set is performed. The current waveforms from $S_{f}$ shows the correct operation of the flyback rectifier in DCM with a frequency switching and a duty cycle equal to $30 \mathrm{kHz}$ and 0.317 , respectively.

The voltage and current waveforms over lamp filaments, during the preheating process, for one T5-8-W UV lamp are illustrated in Fig. 12(a). Filament lamps are preheated for about $2 \mathrm{~s}$ defined inside the microcontroller routine, attending the ANSI standard recommendations. Moreover, the $R_{\mathrm{HC}}$ parameter is also attended according to (2), with $R_{\mathrm{HC}}=5.99$ (with $R_{C}=$ $15.4 \Omega$ ) for T5-8-W UV lamp. These calculations are performed according to the methodology presented in [10].

In Fig. 12(b), voltage and current waveforms are presented for one T5-8-W UV lamp, when it operates in steady state and a switching frequency for the half-bridge inverter stage are equal to $36.39 \mathrm{kHz}$. Resulting, with this parameter, an active power processed through the lamp around $7.92 \mathrm{~W}$, respectively.

The voltage and current output waveforms of the half-bridge inverter stage are shown in Fig. 12(c), where, the voltage applied over the points $\mathrm{A}$ and $\mathrm{B}$ is equal to the voltage over the transistor
$S_{y}$ [see Fig. 6(a)], and the current $i_{\text {inv } T(t)}$ corresponds to the all current sum that flow through the SRPL-filter inductors. Hence, according to this figure, the occurrence of zero voltage switching commutations in this transistor is straightforwardly verified, which improves the electronic-ballast efficiency.

Finally, the active power processed through the lamps are measured, one by one, maintaining the same operation conditions presented previously. When the electronic ballast is equipped with 8-W UV lamps, the total active power processed for the lamp set is approximately $31.82 \mathrm{~W}$, with an input active power of about $41.2 \mathrm{~W}$. Therefore, the overall efficiency is equal to $77.2 \%$.

All experimental results were obtained with a digital oscilloscope (Tektronix-TDS420A), considering the ambient temperature controlled at $25^{\circ} \mathrm{C}$.

\section{B. Water Purification Process}

During the water purification and water collection process, isolation between the hydraulic structure and the elements related to the electronic ballast is guaranteed. Thus, the lamps were placed inside of the purifier chambers and through wires coming out from the purifier structural base, which are interconnected with SRPL filters installed on the purifier bottom/base. In Fig. 13(a), the hydraulic structure and base holder of the 


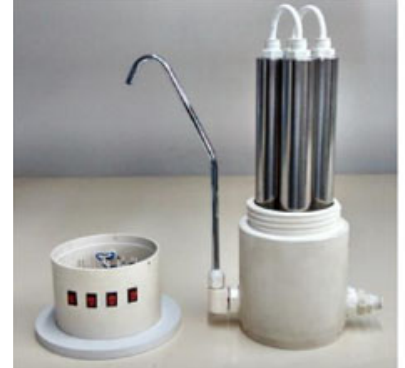

(a)

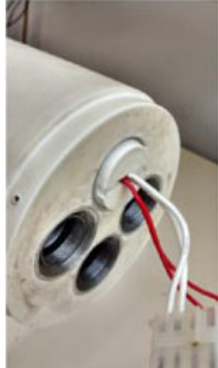

(b)

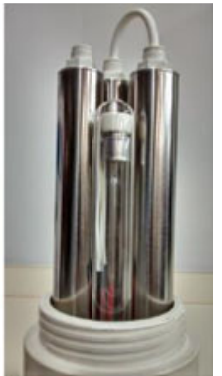

(c)
Fig. 13. Proposed purifier: (a) hydraulic structure and base holder (SRPL Filters); (b) bottom view of the structural base; (c) purifier chambers.

TABLE VIII

FeCAL Coliforms Elimination Analysis

\begin{tabular}{lc}
\hline \hline Purifier Structure & Fecal Coliforms Inactivation \\
\hline Commercial structure & $73 \%$ \\
6-W lamp structure & $97 \%$ \\
8-W lamp structure & $100 \%$ \\
\hline \hline
\end{tabular}

proposed purifier structure are presented. Then, a bottom view of the structural base and the purifier chambers are shown in Fig. 13(b) and (c), respectively. It should emphasize, in order to verify the germicidal/bactericidal action for the proposed purifier, water sample from a stream, without any preliminary treatment process and with fecal and total coliform high concentration was collected in the urban area at Ilha Solteira city (SP, Brazil), with GPS coordinates $20^{\circ} 25^{\prime} 58.4$ 'S 51 20'6.4”W, considering previous analysis performed by Sanitation Laboratory of Civil Engineering, UNESP-Ilha Solteira. These tests were also done under the same conditions for the commercial purifier in order to compare the results in both devices.

Therefore, maintaining the same procedure for each test, about $1 \mathrm{~L}$ of the sample water (infected water) was passed through the purifier, before collecting the samples for biochemical analyses. Thus, purified water samples were collected for the commercial device and for the proposed and implemented equipment, using 6-W UV lamps for both cases, and using 8-W UV lamps only for the proposed purifier. Immediately after collecting some samples, they were taken for analysis at the Sanitation Laboratory cited before, where after standard procedures of water sample dissolution and using the test kit HX021500002 (NKS Endo Coliforms E. Coli), the results presented in Table VIII were obtained.

The results presented in Table VIII reconfirm that the commercial purifier does not meet the minimum values of UV dose required for water disinfection. In addition, in the case of the developed purifier structure, with 6-W UV lamps, there is a fecal coliform inactivation of about $97 \%$, and likewise, it does not guarantee the complete purification according to the NSF/ANSI Standard 55 for class A devices, considering the water sample for purifying without any previous treatment, and the adopted water sample with high level of fecal and total coliforms.
Therefore, considering the sampled water type and its origin, it is possible to affirm that for the microorganism inactivation presents in this water sample, an UV dose greater than $40 \mathrm{~mJ} / \mathrm{cm}^{2}$ will be required. This affirmation can be confirmed with the tests performed for the same water treated by the proposed purifier, when it is equipped with 8-W UV lamps, obtaining a complete inactivation, i.e., $100 \%$ of the fecal coliforms present in water were inactivated.

\section{CONCLUSION}

The proposed methodology, described in this paper, allows the determination and adjustment for the UV dose achieved at immersed T5 UV lamp type water purifiers, with forced flow path, in order to determine the desirable number for the UV lamps, the overall time of UV exposure, and the main parameters for an adequate electronic ballast design, considering high-input power factor, energy saving, and mainly, the desirable level of UV dose for the purifier germicidal action, considering the NSF/ANSI Standard 55 requirements.

The germicidal action ineffectiveness for the commercial UV water purifier, analyzed as a case study in this paper, was demonstrated through its particle flow (hydraulic behavior) and UV radiation studies (UV light intensity values). In addition, considering comparisons to the standard requirements (NSF/ANSI $55)$, the commercial and proposed purifiers were tested and analyzed for an extreme (high level of contamination, fecal, and total coliforms) sample of water. Therefore, considering the available results from the commercial water purifier, one can conclude the extreme necessity for mandatory device certification (drinking water purifiers), due to the necessary validation to its effective germicidal action, considering consumer security and public health policies.

Furthermore, this paper proposes an electronic ballast design featuring ideal preheating for the lamp electrodes, and adjustment for its nominal electric power in steady state for the overall UV lamps. The electronic ballast contains an HPF Flyback rectifier input stage, which could be optimized for lower dc voltage value, considering the voltage level of UV lamps, allowing efficiency improvements in relation to analyzed results in this paper.

Finally, as main work result, a novel water purifier employing ultraviolet radiation was totally designed, and according to adopted models, it can be optimized to perform water microorganism deactivation for class-B devices, where previous treated water is used, or it can be optimized for class A devices, considering the proposed models oriented to their design. Furthermore, it should be noticed the complete (100\%) fecal and total coliforms inactivation for the proposed water purifier, when using the 8-W UV lamp set, considering the contaminated water sample usage.

\section{REFERENCES}

[1] Water Treatment Manual: Disinfection, Office of Environmental Enforcement, Environmental Protection Agency-EPA, Wexford, Ireland, 2011.

[2] Ultraviolet Disinfection Guidance Manual for the Final Long Term 2 Enhanced Surface Water Treatment Rule, Office of Water (4601), U.S. Environmental Protection Agency-EPA 815-R-06-007, Washington, DC, USA, 2006. 
[3] W. J. Masschelein, Ultraviolet Light in Water and Wastewater Sanitation. Brussels, Belgium: Lewis Publishers, 2002.

[4] N. M. Peleato and R. C. Andrews, "Comparison of three-dimensional fluorescence analysis methods for predicting formation of trihalomethanes and haloacetic acids," J. Environ. Sci., vol. 27, pp. 159-167, 2015.

[5] X. lu Zhang, H. wei Yang, X. mao Wang, T. Karanfil, and Y. F. Xie, "Trihalomethane hydrolysis in drinking water at elevated temperatures," Water Res., vol. 78, pp. 18-27, 2015.

[6] S. Pan, W. An, H. Li, M. Su, J. Zhang, and M. Yang, "Cancer risk assessment on trihalomethanes and haloacetic acids in drinking water of china using disability-adjusted life years," J. Hazardous Mater, vol. 280, pp. 288-294, 2014.

[7] B. Ramavandi, S. Farjadfard, M. Ardjmand, and S. Dobaradaran, "Effect of water quality and operational parameters on trihalomethanes formation potential in Dez river water, Iran," Water Resources Ind., vol. 11, pp. 1-12, 2015.

[8] J. Bolton, "Calculation of ultraviolet fluence rate distributions in an annular reactor: significance of refraction and reflection," Water Res., vol. 34, no. 13 , pp. $3315-3324,2000$

[9] S.-C. Wang and Y.-H. Liu, "High-power-factor electronic ballast with intelligent energy-saving control for ultraviolet drinking-water treatment systems," IEEE Trans. Ind. Electron, vol. 55, no. 1, pp. 142-153, Jan. 2008.

[10] F. Wakabayashi, M. de Brito, C. Ferreira, and C. Canesin, "Setting the preheating and steady-state operation of electronic ballasts, considering electrodes of hot-cathode fluorescent lamps," IEEE Trans. Power Electron, vol. 22, no. 3, pp. 899-911, May 2007.

[11] F. Wakabayashi and C. Canesin, "A new model for tubular fluorescent lamps operated at high frequencies for dimmable applications," in Proc. IEEE-ISIE Int. Symp. Ind. Electron, vol. 1, 2003, pp. 490-494.

[12] F. Wakabayashi and C. Canesin, "An improved design procedure for LCC resonant filter of dimmable electronic ballasts for fluorescent lamps, based on lamp model," IEEE Trans. Power Electron, vol. 20, no. 5, pp. 11861196, Sep. 2005.

[13] Ultraviolet Microbiological Water Treatment Systems, NFS/ANSI 55, 2002.

[14] C. Xu, X. Zhao, and G. Rangaiah, "Performance analysis of ultraviolet water disinfection reactors using computational fluid dynamics simulation," Chem. Eng. J., vol. 221, pp. 398-406, 2013.

[15] C. Buchner, "Modelling of UV disinfection reactors by means of computational fluid dynamics," Ph.D. dissertation, Dept. Radiochemistry, Vienna Univ. Techol., Vienna, Austria, 2006.

[16] Y.-T. Hung, N. K. Shammas, and L. K. Wang, Advanced Physicochemical Treatment Processes (Handbook of Environmental Engineering). Totowa, NJ, USA: Humana Press, 2007.

[17] D. Liu, "Numerical simulation of UV disinfection reactors: Impact of fluence rate distribution and turbulence modeling," Ph.D. dissertation, Dept. Civil, Construct., Environ. Eng., North Carolina State Univ., Raleigh, NC, USA, 2004.

[18] Final catalogue Philips UV Purification, Royal Philips Electronics, 2010. [Online]. Available: http://www.lighting.philips.com/pwc_li/eg_en/ application_areas/assets/purification/Final\%20catalogue\%20Philips\% 20UV\%20Purification\%20march\%202010.pdf

[19] F. Wakabayashi and C. Canesin, "Electronic ballast for multiple fluorescent lamp systems," IET Elect. Power Appl., vol. 1, no. 1, pp. 49-58, Jan. 2007.

[20] S. H. Kang, H. Nguyen, D. Maksimovic, and I. Cohen, "Efficiency characterization and optimization in flyback dc-dc converters," in Proc. IEEE Energy Convers. Congr. Expo., Sep. 2010, pp. 527-534.

[21] W. Qiu, W. Wu, K. Rustom, H. Mao, and I. Batarseh, "Bi-flyback singlestage PFC converter with valley switching technique," in Proc. 34th Annu. IEEE Power Electron. Spec. Conf., vol. 2, Jun. 2003, pp. 803-807.

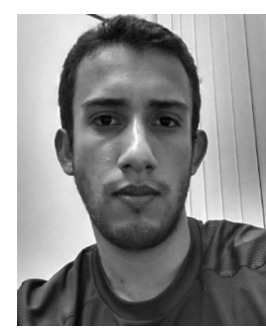

Luis De Oro Arenas (S'12) was born in Cartagena, Colombia. He received the B.Sc. degree in electronic engineering from the National University of Colombia, Bogota, Colombia, in 2012, and the M.Sc. degree from Sao Paulo State University-FE/IS-UNESP, Ilha Solteira, Brazil, in 2014, where he is currently working toward the Ph.D. degree.

His interests include ballast for fluorescent lamps, digital control, power electronics, switching-mode power supplies, and electrical

power quality

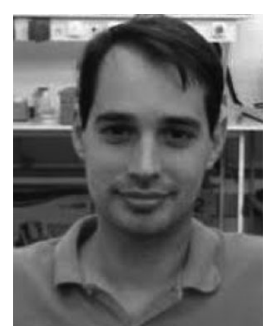

Guilherme de Azevedo e Melo received the Graduate degree in electrical engineering in 2001, the Master's degree in 2006, and the Ph.D. degree in 2010, all from Sao Paulo State University-FE/IS-UNESP, Ilha Solteira, Brazil.

$\mathrm{He}$ has been a member of Power Electronics Laboratory (LEP) and a Collaborator Professor with Sao Paulo State University-FE/IS-UNESP since 2010, His main research interests include power electronics, renewable energy, and electrical vehicles.

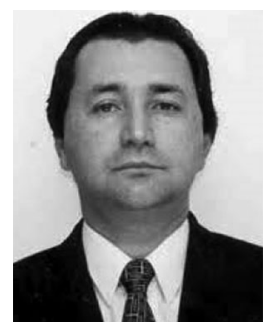

Carlos Alberto Canesin (S'87-M'97-SM'08) received the B.Sc. degree in electrical engineering from Sao Paulo State UniversityFE/IS-UNESP, Ilha Solteira, Brazil, in 1984, and the M.Sc. and Ph.D. degrees in electrical engineering from the Power Electronics Institute, Federal University of Santa Catarina, Florianopolis, Brazil, in 1990 and 1996, respectively.

He started the Power Electronics Laboratory (LEP), FE/IS, UNESP, where he is currently a Full Professor. His research interests include power-quality analysis and techniques, active-power-factor-correction techniques, high-powerfactor rectifiers, soft-switching techniques, dc-to-dc converters, dc-to-ac converters, switching-mode power supplies, solar/photovoltaic energy applications, electronic fluorescent ballasts, and educational research in power electronics.

Prof. Canesin was the President of the Brazilian Power Electronics Society (November 2004-October 2006). He was the Editor-in-Chief of the Brazilian Journal of Power Electronics (2003-2004). Since 2003, he has been an Associate Editor for the IEEE TRANSACTIONS ON POWER ELECTRONICS, and since 2010, he has been a member of The State of Sao Paulo Council for Energy Policy. 